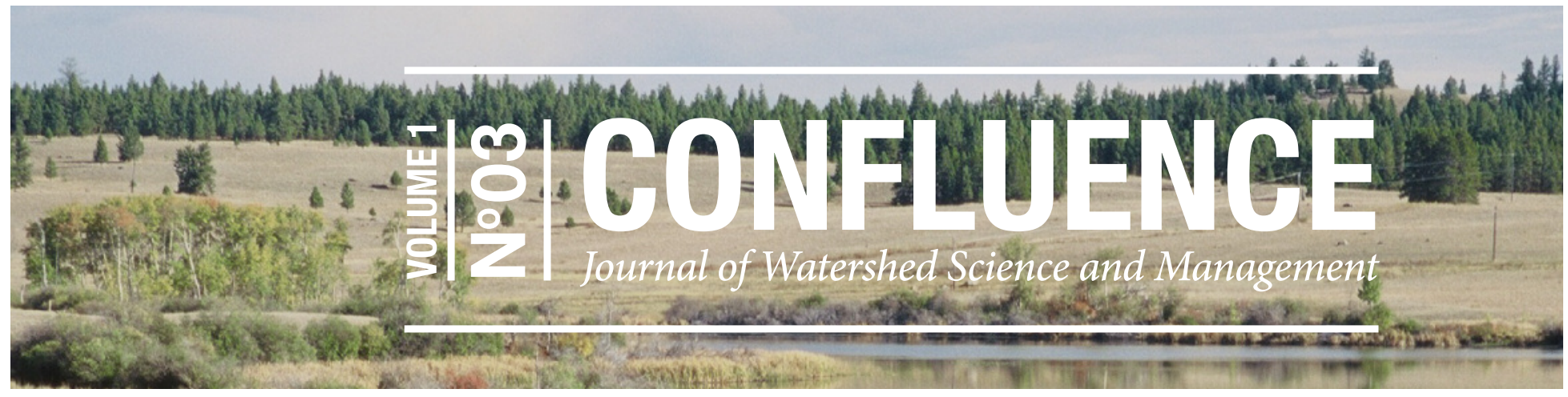

\title{
Efficient Semi-Distributed Hydrological Modelling Workflow for Simulating Streamflow and Characterizing Hydrologic Processes
}

\section{Matthew Chernos, Ryan MacDonald \& James Craig}

\author{
Matthew Chernos is a Hydrologist with MacDonald Hydrology Consultants Ltd. Email: matthew.chernos@machydro.ca \\ Ryan MacDonald is a Hydrologist and President of MacDonald Hydrology Consultants Ltd. and Adjunct Assistant \\ Professor at the University of Lethbridge in the Department of Geography.Email: ryan.macdonald@machydro.ca \\ James Craig is an Associate Professor at the University of Waterloo and the Canada Research Chair in Hydrologic \\ Modelling and Analysis in the Department of Civil and Environmental Engineering.Email: jrcraig@uwaterloo.ca
}

\section{Abstract}

\section{Introduction}

Streamflow records are required for a wide range of industrial, environmental, and urban design applications. However, the sparse distribution of hydrometric stations in western Canada, and their limited spatial and temporal representativeness, necessitate hydrologic regionalization methods to generate streamflow for a point of interest. Here, an efficient semi-distributed hydrological modelling workflow that has modest data requirements and uses publicly available data sources, freely available, open-source data processing tools, and the Raven hydrological modelling framework is presented. First, the workflow is presented by outlining the major steps required for a range of modelling applications. Second, the workflow is applied to simulate streamflow for the Elk River watershed in British Columbia. Finally, the calibrated model is used to quantify glacier contributions to streamflow and investigate the hydrologic response to future climate and land use scenarios. The workflow is scalable, flexible, relies on few statistical assumptions, and is scientifically rigorous. In addition, the resultant model allows the ability to trace the primary sources of streamflow in the region, and for the evaluation of future watershed hydrology due to environmental and climatic change.

\section{KEYWORDS hydrologic modelling; streamflow; watershed modelling}

For many environmental, industrial, and urban applications in western Canada, an assessment of surface water quantity and quality is required for a basin or watershed of interest. In many instances, this may be part of an Environmental Assessment (Alberta ESRD, 2013; British Columbia Ministry of Environment, 2012), though a quantification of surface water is vital for a wide range of topics, including water licensing, flood risk analysis, and watershed assessment. Generating required surface water indicators typically relies on continuous daily streamflow $\left(\mathrm{m}^{3} / \mathrm{s}\right)$ for a region or point of interest. However, the relative paucity of streamflow records, as well as their limited temporal and spatial representativeness, necessitate hydrologic regionalization methods to generate records for an ungauged point of interest.

A rudimentary approach to hydrological regionalization employs empirical scaling relations. Typically streamflow is calculated using a regional record and linear regression to scale the data to a drainage area's point of interest. This approach has the advantage of being easy to implement, and has low data requirements (Razavi \& Coulibaly, 2012). However, it assumes statistical stationarity, synchrony between sites, and the spatio-temporal representativeness of the proxy sites (Rosenberg et al., 2011). These assumptions limit the method, since they rely on coincidal extreme events, and are susceptible to bias introduced by short data records or weak spatial transferability, which can limit the accuracy of simulations (Vogel, 2006). In addition, since this method relies solely on historical data, it cannot reliably account for climatic changes or projected future hydro-climatic regimes (Fernandez et al., 2000). 
As an alternative, modelling the governing hydrologic processes avoids these assumptions. This approach offers the flexibility to simulate a variety of hydrological processes directly, allowing for a model to be chosen to best represent the regional hydrology. Furthermore, the approach provides a tool that can be used to examine watershed processes under a range of current and (potential) future climatic and land use conditions. While data and technical requirements are higher than for empirical scaling relations, hydrologic modelling methods allow for robust, scientifically defensible simulations, flexible model constructions, uncertainty assessment, and a framework to constrain the range of potential hydrologic response to environmental change. This article presents an efficient workflow to simulate watershed hydrology using a semi-distributed hydrological model, publicly available (free) data, open-source tools, and relatively little, readily available input data.

\section{This article:}

1 applies the Raven hydrological modelling framework as part of a general workflow required to generate a working hydrological model;

2 presents specific steps used to simulate streamflow in the Elk River, British Columbia; and

3 demonstrates some potential applications of a calibrated hydrological model relevant to watershed assessments in western Canada.

Raven is a fast and flexible hydrological modelling framework that allows for the simulation of watershed hydrology. Unlike a hydrological model, where a single-model representation of the physical processes is imposed on all watersheds, the Raven hydrological modelling framework allows for the customization of the watershed representation based on data availability, geographic setting, landscape type, process understanding, and project goals (Craig et al., 2016). Most commonly, the practising hydrologist is concerned with water quantity, and therefore will simulate streamflow. However, Raven can be configured to generate additional outputs, such as tracking runoff source areas and a range of system states and fluxes, including: snow-water equivalent; soil wetness; air temperatures; evaporation; and net shortwave/longwave radiation at points of interest. This flexibility gives Raven a wide range of potential applications, some of which will be demonstrated below. Raven is freely available, and can be downloaded at http://www.civil.uwaterloo.ca /jrcraig/Raven/Downloads.html .

Basic Raven model configurations require five input files: (1) a file specifying how to represent the water cycle, including selected algorithms for each hydrological process employed (e.g., the Priestley-Taylor algorithm for potential evaporation, the HBV-EC snowmelt algorithm for snowmelt energy); (2) a file containing values for all model parameters; (3) a spatial file containing land use and terrain data for each Hydrologic Response Unit; (4) a time-series file containing meteorological and, optionally, streamflow data for calibration and verification; and (5) a file containing initial watershed conditions (which can be left blank). For generating these files, $R$ statistical software ( $R$ Core Team, 2016) was utilized for data processing and formatting, as well as post-modelling analysis and data visualization.

\section{Data Requirements Meteorology data}

Daily maximum and minimum air temperatures and precipitation data are required for at least one regionally representative location. Depending on the size and meteorological complexity of the basin, additional meteorological stations may be required to adequately capture variability in precipitation and temperature distributions. In particular, locations with strong directional precipitation and air temperature gradients (such as along the Alberta-British Columbia Continental Divide) will likely require multiple gauges to accurately reproduce this spatial heterogeneity. In addition to the number of stations required for the hydrological model, Raven cannot accommodate missing meteorological values, and missing data must be infilled prior to simulation. Typically, the simplest infilling method involves deriving statistical relations between the site of interest and a nearby meteorological station with available data. Where no suitable nearby station is available, more complex methods, such as splines or interpolation using mean values (e.g., Junninen et al., 2004; Schneider, 2001), or the use of a downscaled climate data set, such as ClimateBC/WNA/NA (Wang et al., 2012), may provide a useful alternative. 


\section{Hydrologic response unit delineation}

To reduce computation time, areas of similar character and location, termed Hydrologic Response Units (HRUs) (e.g., Jost et al., 2012; Stahl et al., 2008), are lumped together and assumed to have a uniform hydrologic response to meteorological inputs. Hydrologic Response Unit delineation typically consists of an overlay of land use, elevation bands, slope, and aspect, while in some instances further spatial datasets, such as vegetation, soil types, or geology, may be used. In heterogenous basins (typically steep, mountainous watersheds), an initial overlay, as would be generated through an intersection operation on the input spatial datasets, can generate a large number of HRUs, many of which will be small and discontiguous. A moving window modal filter can be applied, such as applying the "focal()" function in the R "raster" package (Hijmans \& van Etten, 2012) to reduce the scatter in the HRUs. The filter smooths the raster by finding the mode in a moving window with a user-specified number of grid cells. For input into Raven, the area, elevation, land use class, vegetation class (which in many cases will be the same as the land use class), soil profile, slope, and aspect must be specified for each HRU. Elevation, slope, and aspect can be obtained from the mean value in each HRU, while the longitude and latitude of each HRU (used for interpolation and radiation estimates) can be approximated by its centroid. Vegetation and soil classes for each HRU are often implicitly tied to each land use type, unless additional input layers were employed during HRU delineation.

\section{Additional data}

In general, the use of additional sources of data (beyond basic meteorological and observed streamflow data) have been shown to significantly improve model performance and ensure streamflow is being generated by the correct mechanisms (Finger et al., 2015). Unless all model parameters are known with a high degree of confidence, streamflow data will be required for model calibration and verification. Air temperature and/or precipitation data from climate stations not used as model input are also useful to evaluate the spatial distribution of meteorological variables further from gauged sites. Snow water equivalent (SWE) observations are particularly valuable in watersheds with deep snowpacks, as they provide a secondary calibration or verification dataset, and allow for a verification of the snow accumulation and melt routines, independent of runoff.

\section{Model Setup}

One of the primary benefits of using Raven as a hydrological modelling framework is the flexibility in process and algorithm implementations. Since no hydrological processes are forced upon the user, the user has full flexibility to include (or exclude) processes and define the algorithms used to represent them. For example, in modelling snowmelt, options range from temperature index methods that require only air temperaure, to full energy balance approaches that employ detailed shading and solar geometry calculations. Similarly, the modeller can choose to include one of several available snow sublimation routines of varying complexity, or to exclude the process completely. This flexibility allows Raven to be easily customized to conform to existing conceptual hydrological models, or to examine individual portions of the water balance independently (e.g., only snowmelt or evaporation).

While the user must choose individual processes and algorithms, Raven has also demonstrated nearperfect emulation (Craig et al., 2016) of several popular hydrological models, including HBV-EC (Bergström, 1995), UBC-WM (Quick \& Pipes, 1977), and GR4J (Edijatno et al., 1995), while it employs algorithms from other models, including VIC (Liang et al., 1994). These templates allow for the use of popular (and vetted) conceptual models with the flexibility to include custom processes and/or algorithms. A thorough discussion of model selection for a range of applications can be found in Beckers et al. (2009).

In addition to hydrological processes, the user also has control over global routines, such as the interpolation method between meteorological gauges (if applicable). The modeller can choose to spatially interpolate climate observations using inverse distance weighting or nearest-neighbour methods, or to manually provide a gauge weight to each HRU. Hydrologic routing routines between nested subbasins can also be modified, with options ranging in complexity, including Muskingum-Cunge (Overton, 1966) and diffusive wave routing mechanisms, or simple time-delay calculations. In addition, lakes, reservoir operations, and non-natural inflows or outflows (e.g., industrial treatment output) can all be accounted for within the hydrologic routing of the basin. This flexibility provides a highly customizable hydrological model, and allows for project goals and relevant processes to drive model formulation. 


\section{Parameterization, Calibration, and Model Verification}

The choice of processes and algorithms will dictate which model parameters are required. In almost all cases, calibration will be required to fit simulated values to observed (likely streamflow) data. For instances where streamflow data are only available from a single gauge, the available record should be split. A portion of the record should be used for calibration, while the remainder should be held separate for model verification (Klemeš, 1986). Model parameters can be calibrated using the software tool OSTRICH (Matott, 2005; Matott \& Rabideau, 2008), which can implement a number of optimization algorithms, including dynamically dimensioned search (DDS) (Tolson \& Shoemaker, 2007) and Levenberg-Marquardt (Marquardt, 1963), which are discussed in detail below.

Model calibration and uncertainty analysis typically involves Monte Carlo simulations or a generalized likelihood uncertainty estimation (GLUE) (e.g., Jost et al., 2012; Mahat et al., 2015; Stahl et al., $2008)$ where a large number $(>10,000)$ of uniformly randomly selected parameter sets are generated. However, these methods are computationally intensive (Tolson \& Shoemaker, 2008), and larger models may require long periods of time to calibrate (days or weeks). In contrast, the DDS algorithm reduces computational cost by automatically scaling the search to find a globally optimal solution based on a user-specified maximum number of model iterations (Tolson \& Shoemaker, 2007). This has the advantage of focusing parameter perturbations toward a global maximum and reducing the potential for equifinality, while also significantly reducing the number of model iterations needed to converge on an acceptable solution, making it a more efficient approach (Razavi et al., 2010).

Here, parameter calibration is achieved by first identifying sensitive parameters and then grouping and calibrating process-related parameters in a step-like fashion, broadly following Stahl et al. (2008); the overarching method is outlined in Table 1. First, initial parameter sets are input as a guided "first estimate" and are manually adjusted to roughly emulate the shape and structure of the annual hydrograph. The complete set of parameters is then calibrated using the Levenberg-Marquardt algorithm, 1000 iterations (though this number may vary based on the number of model parameters), and a relatively broad range of parameter values. The sensitivity of each parameter is determined within the OSTRICH software optimization tool using composite scaled sensitivities (CSS) (Hill, 2000; Matott, 2005), and insensitive parameters $(\mathrm{CSS} \approx 0)$ are excluded from further calibration steps. In further steps, calibration for sensitive parameters is executed in process-based groups (Table 1) using the DDS algorithm. This sensitivity screening significantly reduces the number of parameters considered in calibration, leading to a significantly reduced computational cost.

Table 1: Framework for parameter calibration, where the subscript $Q$ represents daily streamflow, while MAF designates mean annual flow.

\begin{tabular}{|c|c|c|c|}
\hline & Guiding Principle & Parameters & Criteria/Objective \\
\hline 1. & Isolate and exclude insensitive parameters & All & $\begin{array}{l}C S S \approx 0 \\
\text { ("not calculated") }\end{array}$ \\
\hline 2. & Ensure correct volume of water in catchment & $\begin{array}{l}\mathrm{T}, \mathrm{P} \text { lapse rates, } \\
\text { Interception, glacier melt }\end{array}$ & $\begin{array}{l}\text { Minimize } P B I A S_{Q} \\
\text { Maximize } N S E_{M A F}\end{array}$ \\
\hline 3. & Ensure correct freshet timing & T lapse rate, melt factors & $\begin{array}{l}\text { Maximize } N S E_{Q} \\
\text { Ensure SWE timing }\end{array}$ \\
\hline 4. & Calibrate routing, sensitivity, and baseflow & Soil routing parameters & Maximize $N S E_{Q}$ \\
\hline 5. & Approximate parameter uncertainty & All & Obtain parameter $S E$ \\
\hline
\end{tabular}

Note: NSE is the Nash-Sutcliffe Efficiency, CSS is the composite scaled sensitivity, and PBIAS is the percent bias, while the subscript Q represents daily streamflow and MAF designates mean annual flow. T and $P$ correspond to air temperature and precipitation.

Second, the simulated annual water yield in the catchment is corrected to mean annual flow (MAF) by calibrating water balance parameters, such as the precipitation and air temperature lapse rates, canopy interception, and glacier melt (if applicable). Third, freshet timing is calibrated to daily streamflow by calibrating the air temperature lapse rate and melt parameters for each land use type (in snowmeltdominated basins such as the one presented in this study). If snow water equivalent (SWE) data are available, the melt timing and peak SWE values can be directly compared, while an additional qualita- 
tive inspection can be carried out over a range of HRUs (selected to span elevations and aspects) to ensure realistic accumulation and melt rates. It should be noted that in basins where snowmelt is modest or nonexistent, this step may be omitted, as the model will not be sensitive to changes in these parameters (and many may not even be included in the model). Fourth, water routing and streamflow responsiveness is calibrated using routing parameters. Steps two through four are repeated as necessary until satisfactory model performance is met. Once an adequate model solution is found, a final refinement calibration run is implemented for all sensitive parameters using the Levenberg-Marquardt algorithm in order to derive uncertainty statistics such as the standard error. Model fit is evaluated during calibration runs using the Nash-Sutcliffe Efficiency (NSE) (Nash \& Sutcliffe, 1970). In some cases, calibration runs may be improved by minimizing the (absolute) percent bias (PBIAS) as a secondary objective function. Raven supports the direct calcualtion of these diagnostic metrics (and many others), if provided with an observed streamflow time series.

Once the model has demonstrated satisfactory performance, model strengths and liminations should be evaluated using independent verification data. Common hydrology summary statistics, such as the Nash-Sutcliffe Efficiency and Percent Bias, are evaluated using simulated and observed streamflow values (Moriasi et al., 2007). While the decision to verify the model using a daily or monthly time step will likely depend on project scope and goals, additional diagnostic measures will offer a much improved view on the strengths and weaknesses of the model. For instance, average seasonal or monthly NSE calculations (or absolute differences) will show when model performance is good, and can better elucidate processes that are (or are not) performing well.

\section{Case Study}

\section{Study Site}

The Elk River is located in southeastern British Columbia, immediately west of the Continental Divide and the Alberta border (Figure 1). The watershed originates at Elk Pass and drains south through Sparwood and Fernie, B.C., before reaching its confluence with the Kootenay River at Lake Koocanusa, B.C. The Elk River watershed has received considerable attention recently, with substantial land use from the mining sector resulting in water quality concerns (Kuchapski \& Rasmussen, 2015), in addition to extensive forestry and recreation development. The Elk River is home to important native species, such as the westslope cutthroat trout (Oncorhynchus clarkii lewisi), which are threatened by climate change throughout their native range (Muhlfeld et al., 2017). In addition to supporting an important fishery, the Elk River supports a wide range of social, cultural, and economic values.

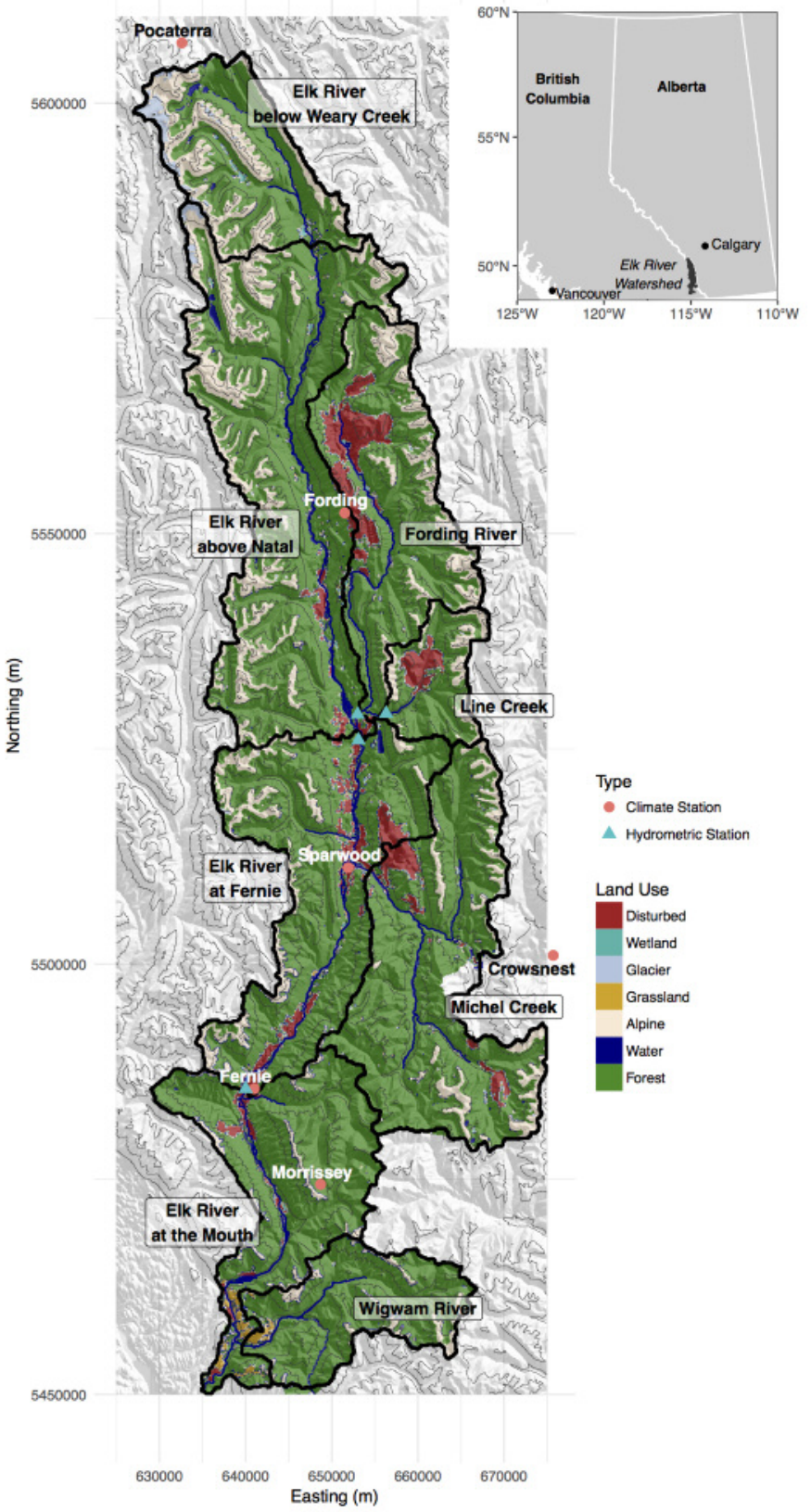

Figure 1: Map of Elk River Watershed study area. Contours are $500 \mathrm{~m}$. 
The watershed ranges in elevation from $760 \mathrm{~m}$ (above sea level) at Lake Koocanusa to $3450 \mathrm{~m}$ at Mount Joffre, and drains $3090 \mathrm{~km}^{2}$ at Fernie, BC. Climate normals from 1980 to 2010 (Environment Canada, 2015) show that west of the watershed, Fernie, BC, receives an average of $1227 \mathrm{~mm}$ of precipitation annually, while northeast and east of the watershed, Sparwood, $\mathrm{BC}$, and Coleman/Crowsnest, $\mathrm{AB}$, are much more arid, and only receive an average of $613 \mathrm{~mm}$ and $582 \mathrm{~mm}$ annually. Air temperatures display a strong seasonal continental pattern; monthly average of the maximum daily temperatures peak in August $\left(25.1^{\circ} \mathrm{C}\right.$ at Fernie) and reach a minimum in December $\left(-3.4^{\circ} \mathrm{C}\right.$ in Sparwood, $-1.9^{\circ} \mathrm{C}$ in Fernie).

The watershed experiences heavy snowfall during the winter months (Environment Canada, 2015), and the northern headwaters also contain several small glaciers. Lower elevations in the watershed are forested, primarily by coniferous trees (in various states of hydrologic recovery from natural disturbance and timber harvest), while higher elevations are bare alpine meadows. The watershed contains several large open-pit coal mines, totalling $184 \mathrm{~km}^{2}$ of area; most notably, the Fording River watershed contains $68.25 \mathrm{~km}^{2}$ of disturbed area (HectaresBC, 2006)

\section{Data Sources}

Daily streamflow data $\left(\mathrm{m}^{3} / \mathrm{s}\right)$ were available for several sites within the Elk River watershed from Water Survey of Canada (2016) hydrometric stations. Two sites were available on the mainstem, while two additional sites were available on major tributaries (Table 2).

Table 2: Water Survey of Canada hydrometric gauges used in this study.

\begin{tabular}{lccc}
\hline Station Name & Station Number & Years & Area $\left.\mathbf{( k m}^{2}\right)$ \\
\hline Line Creek at the Mouth & 08NK022 & $1971-2014$ & 138 \\
\hline Fording River at the Mouth & 08NK018 & $1970-2015$ & 621 \\
\hline Elk River near Natal & 08NK016 & $1950-2015$ & 1840 \\
\hline Elk River at Fernie & 08NK002 & $1925-2015$ & 3090 \\
\hline
\end{tabular}

Daily climate data (maximum, minimum, and mean air temperatures and precipitation) to drive Raven were obtained from five Environment Canada (2016) climate stations (Table 3). Data were available from 1980-2015; however, gaps in the datasets necessitated infilling using nearby climate stations. Air temperature data were infilled by fitting a linear regression model to an adjacent site. Daily precipitation data were imputed using the relative (percent) difference in daily precipitation totals for overlapping events with a nearby adjacent site. All air temperature regressions ranged from $r^{2}=0.90-0.98$, while relationships for net precipitation ranged from $r^{2}=0.40-0.50$. An additional climate station, Morrissey Ridge (British Columbia Ministry of Forests, Lands and Natural Resource Operations, 2015), contained temperature and snow water equivalent (SWE) data from 1983-2013, and was used in model verification. It was therefore excluded from infilling routines.

Table 3: Climate data used in this study.

\begin{tabular}{lccccc}
\hline Site & Latitude & Longitude & Elevation & Climate ID & Network \\
\hline Kananaskis Pocaterra & $50^{\circ} 43^{\prime} 45^{\prime \prime} \mathrm{N}$ & $115^{\circ} 07^{\prime} 12^{\prime \prime} \mathrm{W}$ & 1610 & 3053604 & EC \\
\hline Fording River Cominco & $50^{\circ} 08^{\prime} 55^{\prime \prime} \mathrm{N}$ & $114^{\circ} 51^{\prime} 18^{\prime \prime} \mathrm{W}$ & 1585 & 1152899 & $\mathrm{EC}$ \\
\hline Crowsnest & $49^{\circ} 37^{\prime} 39^{\prime \prime} \mathrm{N}$ & $114^{\circ} 28^{\prime} 55^{\prime \prime} \mathrm{W}$ & 1303 & $3051 \mathrm{R} 4 \mathrm{R}$ & $\mathrm{EC}$ \\
\hline Sparwood & $49^{\circ} 44^{\prime} 43^{\prime \prime} \mathrm{N}$ & $114^{\circ} 52^{\prime} 58^{\prime \prime} \mathrm{W}$ & 1138 & 1157630 & EC \\
\hline Fernie & $49^{\circ} 29^{\prime} 19^{\prime \prime} \mathrm{N}$ & $115^{\circ} 04^{\prime} 24^{\prime \prime} \mathrm{W}$ & 1001 & 1152850 & EC \\
\hline Morrissey Ridge & $49^{\circ} 27^{\prime} 00^{\prime \prime} \mathrm{N}$ & $114^{\circ} 58^{\prime} 00^{\prime \prime} \mathrm{W}$ & 1800 & 2 2C09Q & FLNRO \\
\hline
\end{tabular}

Note: EC refers to Environment Canada, while FLNRO refers to the British Columbia Ministry of Forests, Lands and Natural Resource Operations (2015). 
A digital elevation model (DEM) for the region was required to generate HRUs, and was obtained from the Canadian Digital Elevation Model Mosaic (Natural Resources Canada, 2016). The DEM has a spatial resolution of $20 \mathrm{~m}$, an average horizontal accuracy of $21.8 \mathrm{~m}$, an estimated altimetric accuracy for the region of 10-15 m, and was derived from data taken during the period of 1984-1990. Slope and aspect were obtained from the DEM using the "terrain()" function within the R "raster" package (Hijmans \& van Etten, 2012). Land use data for the region were obtained from HectaresBC (2006) at $100 \mathrm{~m}$ resolution, where the data are classified in seven land use groups: forest, grassland, alpine, water, wetlands, human, and glacier. Hydrologic Response Units were delineated by the overlay of five subbasins, three slope classes $\left(<15^{\circ}, 15^{\circ}\right.$ to $\left.30^{\circ},>30^{\circ}\right)$, four aspects (north, east, south, west), $100 \mathrm{~m}$ elevation bands, and land use passed through a three by three cell focal (modal) filter. In total, 3213 HRUs were generated for the watershed. The number of HRUs could likely be significantly reduced using the HRU discretization approach of Liu et al. (2016), however the model runtime was sufficiently fast (approximately 450 seconds on a MacBook Pro [mid-2010] with a $2.4 \mathrm{GHz}$ Intel Core 2 Duo for a tenyear daily time step simulation), and therefore no further attempt was made to reduce the number of HRUs for computational expediency. For general practice, removing HRUs that have relatively small spatial coverage and/or hydrological influence is recommended. Note that the above model customization would not be feasible if using a standard off-the-shelf model, where all of the process algorithms are typically hard-coded, but is readily implemented within a flexible framework such as Raven.

\section{Hydrological Model}

The watershed was simulated with Raven using a modified version of the HBV-EC; a Canadian version of the original Scandinavian watershed model developed by Environment Canada (Bergström et al., 1995; Canadian Hydraulics Centre, 2010). Precipitation intercepted by the canopy was simulated following Hedstrom and Pomeroy (1998), where the rate of interception was controlled by the leaf area index and vegetation cover defined for each land use type. Precipitation that is not intercepted reaches the soil as SWE or rain. Snowmelt was calculated using a spatially corrected temperature index model, which has been shown to perform well basin-wide over a variety of regions and environments over a daily time step (Hock, 2003; Jost et al., 2012). The method is particularly effective in data-poor mountainous regions, where the lack of spatially distributed solar radiation, wind speed, and humidity observations make alternatives, such as a full energy balance method, impractical. Snowmelt $(M)$ was computed for each HRU as a function of daily air temperature $\left(\mathrm{T}_{\text {air }}\right)$, where:

$$
M=M_{p} C_{f}\left[1-C_{a} \sin (s) \cos (a)\right] T_{a i r}
$$

and $M_{p}$ is a global base melt factor $\left(\mathrm{mm} / \mathrm{d} /{ }^{\circ} \mathrm{C}\right)$ that varies sinusoidally between a maximum and minimum at summer and winter solstices, accounting for seasonal variations in solar radiation related to day length. The global base melt factor was corrected for vegetation cover $\left(\mathrm{C}_{f}\right)$ to account for the effect of forest cover on shading. A further correction was applied to account for the global sensitivity $\left(\mathrm{C}_{a}\right)$ of the melt factor to the slope $(s)$ and aspect $(a)$ of each HRU. In glaciated HRUs, once the snow has been depleted, glacial ice is melted following the above snowmelt routine with a correction factor (calibrated to 3.55 in this model) to account for the higher melt rate of glacier ice due to the much lower albedo of ice relative to snow. Glacial water storage and release were simulated using the HBV-EC algorithms.

Snowmelt, glacial ice melt, and rainfall become surface water, which then infiltrate the three-layer soil. Soils were treated as a three-bucket model. In the uppermost layer, soil water was directed downward by percolation and upward by capillary rise. In the lowest two layers, soil water can return to the surface as baseflow; the response in the middle soil layer was modelled as a fast response, while the response in the deepest layer was slower. Unlike the HBV-EC model, baseflow in the deepest soil layer was simulated using the Variable Infiltration Capacity (VIC) routine (Clark et al., 2008), which allows the baseflow response in this layer to vary as a function of the available soil water.

\section{Model Calibration and Verification}

The model was calibrated using streamflow $\left(\mathrm{m}^{3} / \mathrm{s}\right)$ records from Water Survey of Canada hydrometric gauges Elk River at Fernie and Fording River at the Mouth, from 2000-2010, following the methodology outlined above. The model was most sensitive to the precipitation and adiabatic temperature lapse rates, snowmelt correction factor for forest land use types, and baseflow coefficients for the deepest soil layer (Figure 2). 


\section{Elk River at Fernie}

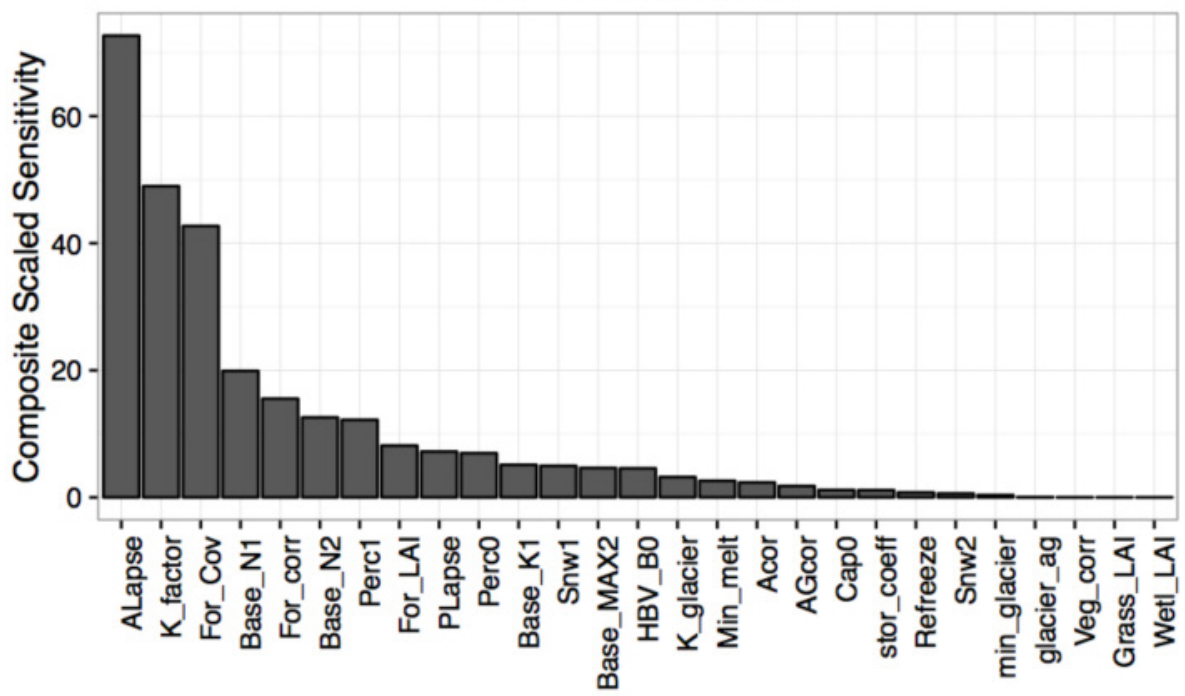

Figure 2. Composite scaled sensitivities for all calibrated parameters relative to the Elk River at Fernie hydrometric station.

The model was verified for the period between 1990-2000 and 2010-2014 for Elk River at Fernie, and Fording River at the Mouth, and for the entire period 1990-2014 for the other regional hydrometric gauges. Performance statistics for streamflow are summarized in Table 4, and hydrographs are plotted in Figure 3. In addition, meteorology and snowpack were verified at Morrissey Ridge.

Simulated SWE showed good agreement with observations $\left(r^{2}=0.82, P B I A S 4.2 \%\right)$, while maximum daily air temperatures were also well-emulated $(N S E=0.88)$. In general, streamflow was well simulated throughout most of the year. Small deviations were observed during the fall, when streamflow was over-predicted, and during the late winter, when flows were under-predicted. There was strong agreement in average and 10th and 90th quantile flows from April to August (Figure 3).

Table 4: Performance statistics Nash-Sutcliffe Efficiency (NSE) and Percent Bias (PBIAS) for Elk River watershed hydrometric model.

\begin{tabular}{|c|c|c|c|c|}
\hline \multirow{2}{*}{ Site } & \multicolumn{2}{|c|}{ Calibration } & \multicolumn{2}{|c|}{ Verification } \\
\hline & NSE & PBIAS (\%) & NSE & PBIAS (\%) \\
\hline Elk River at Fernie & 0.91 & 1.2 & 0.92 & -7.2 \\
\hline Elk River near Natal & - & - & 0.91 & 2.7 \\
\hline Fording River at the Mouth & 0.82 & 7.9 & 0.84 & -1.6 \\
\hline Line Creek above Diversions & - & - & 0.86 & -6.0 \\
\hline
\end{tabular}

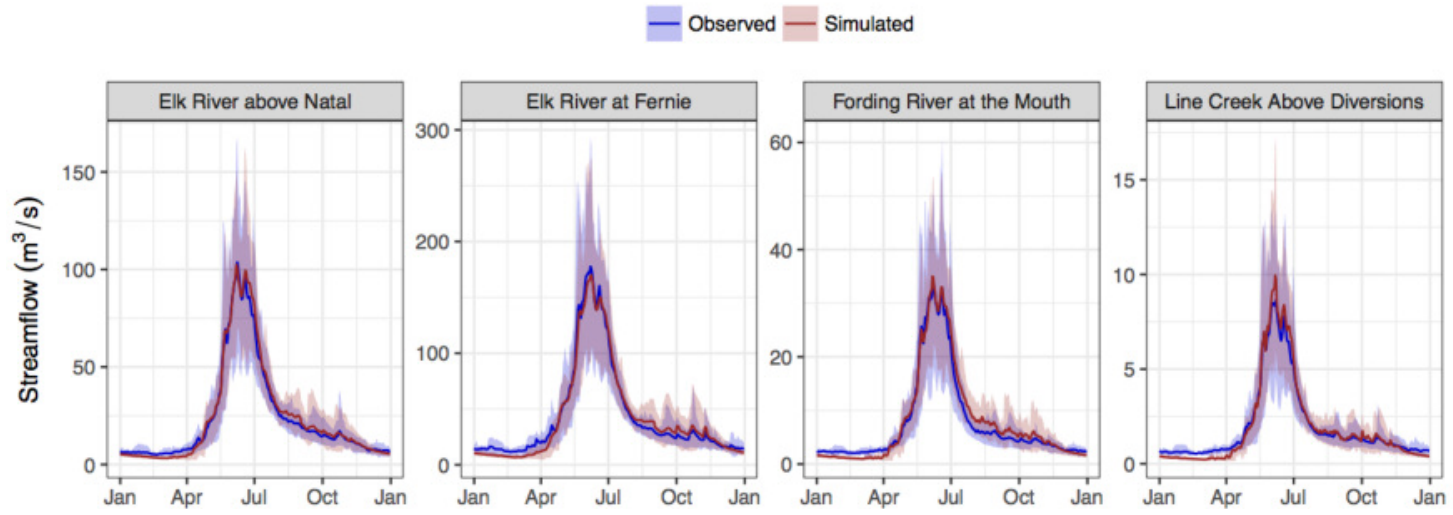

Figure 3. Simulated and observed hydrographs for four Elk Valley WSC hydrometric stations from 1990-2010. Lines correspond to average daily streamflow for the period, while shaded lines correspond to 10th and 90th quantiles. 
Model Applications and Limitations
Once the model has been built and its performance verified, streamflow predictions can be made with good (known) confidence. While in many cases this may be all that is required for the project, a calibrated model based on underlying physical processes offers the opportunity to simulate a wide range of scenarios and calculate various hydrological indicators. The flexibility in using Raven allows for a wide variety of potential scenarios, including various climate scenarios that involve changing meteorological forcings in the model, and land use changes that involve modifying or generating new HRUs. The choice of scenario (if any) will be informed by the project objectives and requirements; however, they will also be limited by model performance, the reliability of input data, and the development and parameterization of the hydrological model. An important consideration for all applications is how well the model represents physical processes. This is particularly true for scenario analyses; if the physical process governing the scenario is not adequately represented in the model (or emulated at all), the simulated response will be unreliable. For instance, when examining the effect of forestry on snowmelt over a basin, it is essential to ensure that the relative vegetation cover and slope/aspect corrections adequately capture the relative differences in the two sites, and recognize what processes are (and are not) accounted for in the simulation. Additionally, this model simulates snowmelt using a temperature index approach that, while it does not provide the same potential precision as a fully distributed energy balance approach, requires substantially less input data, and subsequently less assumptions of how those data are spatially distributed. This sort of trade-off is ubiquitous, and should be informed by, among other factors, data availability, the physical environment, and project goals. In all cases, the underlying assumptions implicit in the modelling scenario play an important role in the simulated results, and remain the responsibility of the modeller. Below, several common scenarios that could be of interest to a wide range of practitioners are presented.

\section{Land Use Change}

Changes in land use can be simulated directly by modifying the HRU file, given that land use/cover is a direct input into the hydrological model. Here, a first order estimate of forest removal is presented (Figure 4). A random sample of forested HRUs in the uppermost subbasin (Elk River below Weary Creek) was converted from "Forest" to "Grassland." The land use change totalled $74.25 \mathrm{~km}^{2}$; 23.0 percent of the headwaters basin and 1.5 percent of the entire Elk River watershed. Simulated results displayed a slightly earlier spring freshet in the headwaters, and lower streamflow in the summer (July-September). The effect of forest removal was more pronounced further upstream, but still had a discernible impact on average late-summer streamflow at the Elk River above Natal hydrometric station.

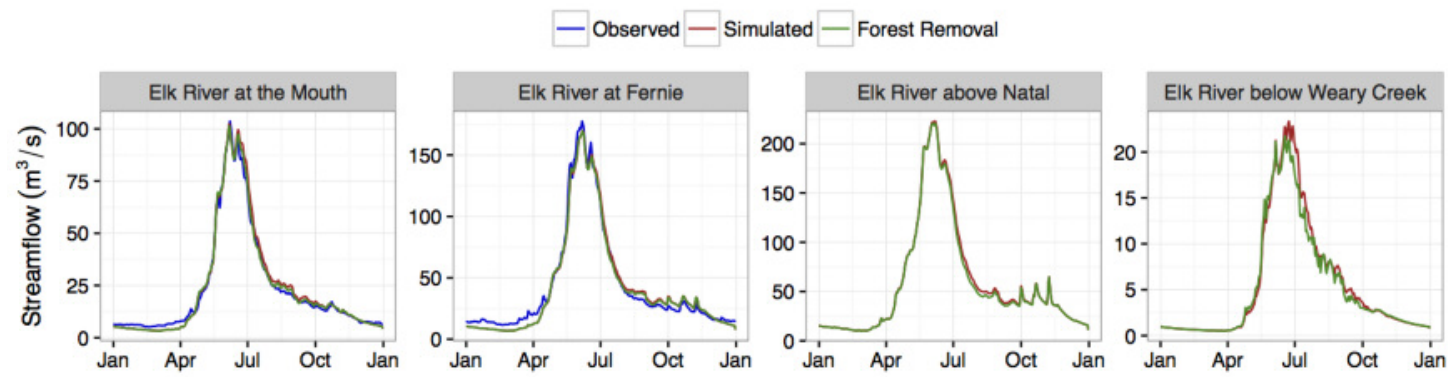

Figure 4. Daily average observed, simulated, and forest removal scenario (simulated) streamflow for four points of interest along the Elk River.

\section{Glacier Contributions to Streamflow}

The percentage contribution to streamflow of any HRU, or group of HRUs, can be accounted for using built-in cofiguration-independent tracer algorithms within Raven. This allows the user to quantify the streamflow contributions over a location or land use type of interest. Here, contributions for all glacier HRUs in the watershed are presented (Figure 5). Their percent contribution was averaged by the day of year for four locations along the mainstem. Elk River at the Mouth is the most downstream point in the watershed, while Elk River below Weary Creek is a headwaters subbasin encompassing $334 \mathrm{~km}^{2}$; all over $1575 \mathrm{~m}$ (above sea level). Results suggest that glaciers in the watershed are relatively minor contributors to streamflow throughout much of the year, though they can be substantial contributors (8-11\% at Elk River below Weary Creek) during the late summer. 


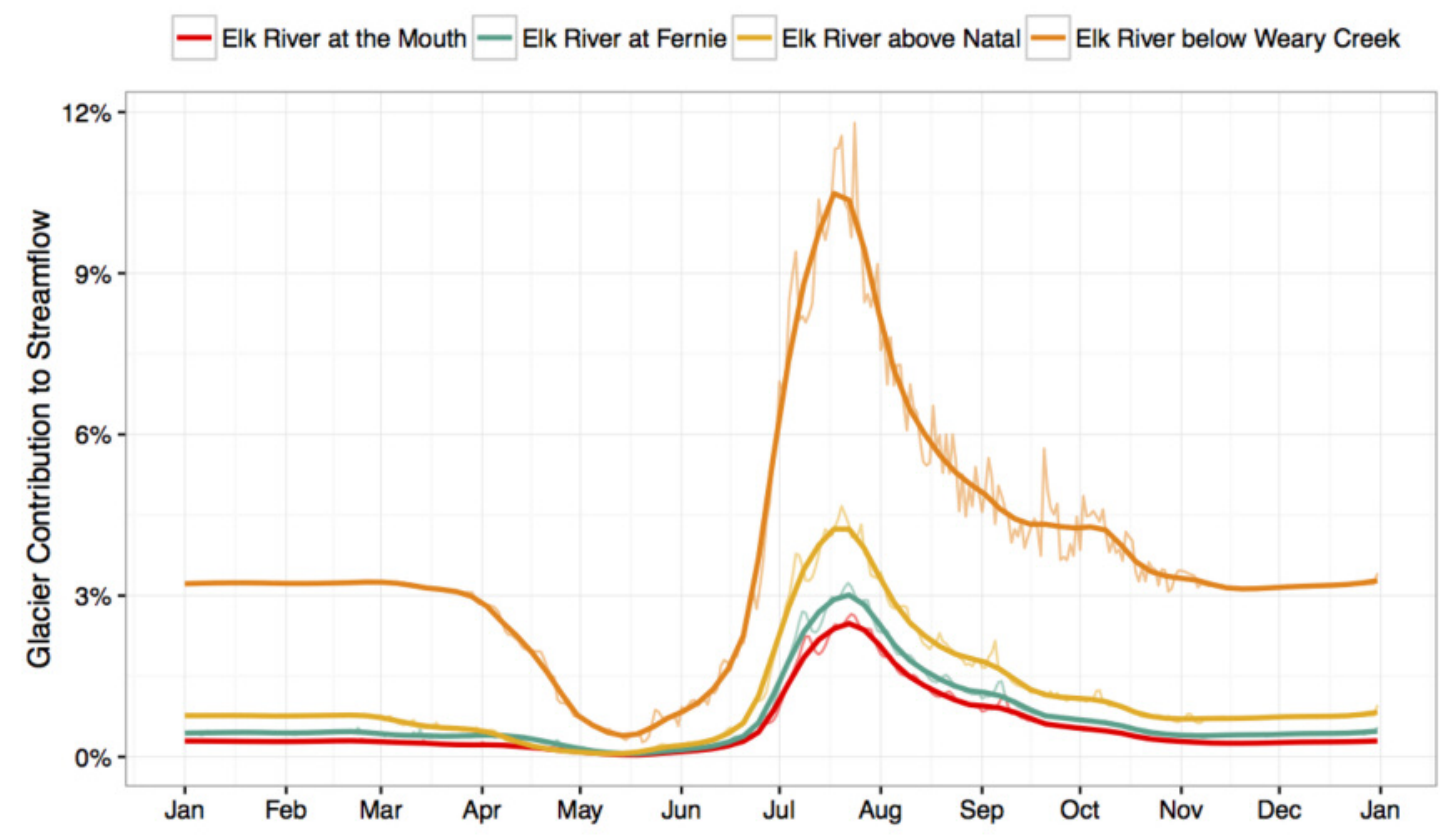

Figure 5. Average daily glacier contribution to streamflow for four locations on the Elk River, B.C. Thin lines represent daily average for the period 2000-2010, while the thicker line is the LOESS smoothed trend.

\section{Climate Change Simulations}

Another common application of a calibrated hydrological model is the simulation of the impact of future climate change (Intergovernmental Panel on Climate Change, 2014; Liverman, 2007) on streamflow. Here, a simple climate change scenario is presented by scaling historical climate data used in the model. Scaling factors were obtained from ClimateWNA (Wang et al., 2012) for each climate station location by calculating the absolute monthly difference in maximum, minimum, and mean air temperatures, and relative (percentage) difference in monthly precipitation between the CanESM2 RCP 4.52025 model and 1980-2010 climate normals. Simulations show an earlier and larger average freshet for all four locations, with minimal changes in winter and fall (low) flow (Figure 6). It should be noted that this first-order estimate does not include changes to land cover, most notably glacier area change, which would further complicate streamflow response.

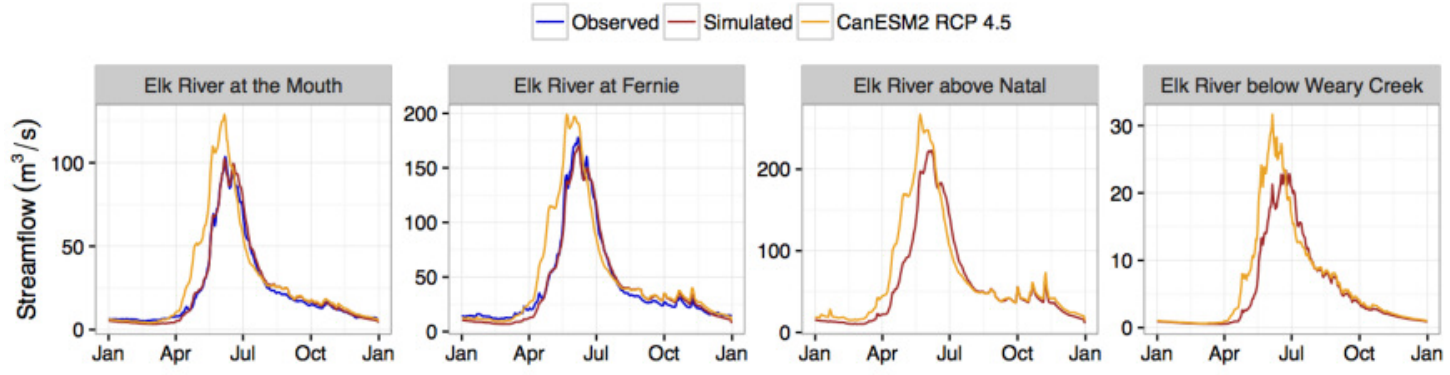

Figure 6. Daily average streamflow for four points of interest along the Elk River, showing observed, simulated, and the RCP 4.5 climate change scenario.

\section{Conclusion}

This article has presented an efficient workflow to simulate watershed hydrology with modest data requirements and a robust scientific framework. Streamflow simulations derived using this workflow rely on few statistical assumptions, are rooted in governing hydrological processes, and allow for flexible model development and parameterization. This allows for a more holistic understanding of the watershed of interest, while relying on the governing physical processes to dictate output. Ultimately, this enables model scalability beyond the gauge and time period of record, allowing for long-term assessment of hydrologic change. This method presents many options to extend the analysis and examine a suite of scenarios, including climate change, land use change, and assessing the primary processes governing streamflow generation. The relative ease, scientific robustness, and 
high degree of flexibility make this method of semi-distributed hydrologic modelling an effective and efficient workflow to generate streamflow records and examine watershed hydrology for a wide range of industrial, environmental, and urban applications. ducted in the Elk River Watershed, and for the anonymous reviewers and editor for their helpful suggestions, which have improved the content and clarity of this submission.

\section{References}

Alberta ESRD. 2013. Guide to preparing environmental impact assessment reports in Alberta. Edmonton, AB: Alberta Government.

Beckers, J., B. Smerdon, T. Redding, A. Anderson, R. Pike, \& A.T. Werner. 2009. Hydrologic models for forest management applications: Part 1: Model selection. Streamline Watershed Management Bulletin 13: 35-44.

Bergström, S. 1995. The HBV model. In Singh, V.P. (Ed.), Computer models of watershed hydrology (pp. 443-476). Highlands Ranch, CO: Water Resources Publications.

British Columbia Ministry of Environment. 2012. Technical guidance 6: Water and air baseline monitoring guidance document for mine proponents and operators. Victoria, BC: Environmental Sustainability and Strategic Policy Division.

British Columbia Ministry of Forests, Lands and Natural Resource Operations. 2015. River forecast centre: Automated snow pillow data. URL: http://bcrfc.env.gov.bc.ca/data/asp/ (Accessed April 10, 2015).

Canadian Hydraulics Centre. 2010. Green Kenue reference manual. Ottawa, ON: National Research Council.

Clark, M.P., A.G. Slater, D.E. Rupp, R.A. Woods, J.A. Vrugt, H.V. Gupta, T. Wagener, \& L.E. Hay. 2008. Framework for understanding structural errors (fuse): A modular framework to diagnose differences between hydrological models. Water Resources Research 44(12): 1-14.

Craig, J.R., S. Huang, A. Khedr, S. Pearson, S. Spraakman, G. Stonebridge, C. Werstuck, \& C. Zhang. 2016. Raven: user's and developer's manual. Raven Version 2.1. URL: http://www.civil.uwaterloo .ca/jrcraig/Raven/Main.html (Accessed August 10, 2016).

Edijatno, N.O., X. Nascimento, Z. Yang, \& C. Michel Makhlouf. 1999. GR3J: A daily watershed model with three free parameters. Hydrological Sciences Journal, 44(2): 263-278.

Environment Canada. 2015. Canadian climate normals 1980-2010. URL: http://climate.weather.gc .ca/climate_normals (Accessed August 20, 2015).

Environment Canada. 2016. Historical climate data. URL: http://climate.weather.gc.ca/ (Accessed February 3, 2016).

Fernandez, W., R. Vogel, \& A. Sankarasubramanian. 2000. Regional calibration of a watershed model. Hydrological Sciences Journal, 45(5): 689-707.

Finger, D., M. Vis, M. Huss, \& J. Seibert. 2015. The value of multiple data set calibration versus model complexity for improving the performance of hydrological models in mountain catchments. Water Resources Research, 51(4): 1939-1958.

HectaresBC. 2006. Land Cover Raster, British Columbia. URL: http://www.hectaresbc.org/app/habc /HaBC.html (Accessed July 1, 2016).

Hedstrom, N., \& J. Pomeroy. 1998. Measurements and modelling of snow interception in the boreal forest. Hydrological Processes, 12(1011): 1611-1625.

Hijmans, R.J., \& J. van Etten. 2012. raster: Geographic analysis and modeling with raster data. $\mathrm{R}$ package version 2.0-12 (Accessed June 21, 2016).

Hill, M. C. 2000. Methods and guidelines for effective model calibration. In Building Partnerships (pp. 1-10). Proceedings from the Joint Conference on Water Resource Engineering and Water Resources Planning and Management. July 30-August 2, 2000. Minneapolis, Minnesota. doi.org/10.1061/40517(2000)18. 
Hock, R. (2003). Temperature index melt modelling in mountain areas. Journal of Hydrology, 282(1): $104-115$.

Intergovernmental Panel on Climate Change. 2014. (R.K. Pachauri, \& L.A. Meyer [eds.]). Climate Change 2013: The Physical Science Basis: Working Group I Contribution to the Fifth Assessment Report of the Intergovernmental Panel on Climate Change. Geneva, Switzerland: Cambridge University Press.

Jost, G., R. Moore, B. Menounos, \& R. Wheate. 2012. Quantifying the contribution of glacier runoff to streamflow in the upper Columbia River Basin, Canada. Hydrology and Earth System Sciences, 16(3): 849-860.

Junninen, H., H. Niska, K. Tuppurainen, J. Ruuskanen, \& M. Kolehmainen. 2004. Methods for imputation of missing values in air quality data sets. Atmospheric Environment, 38(18): 2895-2907.

Klemeš, V. 1986. Operational testing of hydrological simulation models, Hydrological Sciences Journal, 31(1): 13-24. doi: 10.1080/ 02626668609491024

Kuchapski, K.A., \& J.B. Rasmussen. 2015. Surface coal mining influences on macroinvertebrate assemblages in streams of the Canadian Rocky Mountains. Environmental Toxicology and Chemistry, 34(9): 2138-2148.

Liang, X., D.P. Lettenmaier, E.F. Wood, \& S.J. Burges. 1994. A simple hydrologically based model of land surface water and energy fluxes for general circulation models. Journal of Geophysical Research: Atmospheres, 99(D7): 14415-14428.

Liu, H., B.A.Tolson, J.R. Craig, \& M. Shafii. 2016. A priori discretization quality metrics for semidistributed hydrological models. Journal of Hydrology, 543B: 873-891.

Liverman, D. 2007. From uncertain to unequivocal. Environment: Science and Policy for Sustainable Development, 49(8): 28-32.

Mahat, V., A. Anderson, \& U. Silins. 2015. Modelling of wildfire impacts on catchment hydrology applied to two case studies. Hydrological Processes, 29(17): 3687-3698.

Marquardt, D.W. 1963. An algorithm for least-squares estimation of nonlinear parameters. Journal of the Society for Industrial \& Applied Mathematics, 11(2): 431-441.

Matott, L.S. 2005. OSTRICH: An Optimization Software Tool; Documentation and User's Guide. Version 1.8. URL: http://www.eng.buffalo.edu/ lsmatott/Ostrich/OstrichMain.html

Matott, L.S., \& A.J. Rabideau. 2008. Calibration of complex subsurface reaction models using a surrogate-model approach. Advances in Water Resources, 31(12): 1697-1707.

Moriasi, D.N., J.G. Arnold, M.W. Van Liew, R.L. Bingner, R.D. Harmel, \& T.L. Veith. 2007. Model evaluation guidelines for systematic quantification of accuracy in watershed simulations. Transactions of the ASABE, 50(3): 885-900.

Muhlfeld, C.C., R.P. Kovach, R. Al-Chokhachy, S.J. Amish, J.L. Kershner, R.F. Leary, W.H. Lowe, G. Luikart, P. Matson, D.A. Schmetterling, \& B.B. Shepard. 2017. Legacy introductions and climatic variation explain spatiotemporal patterns of invasive hybridization in a native trout. Global Change Biology, 00: 1-11.

Nash, J. \& J.V. Sutcliffe. 1970. River flow forecasting through conceptual models part i: A discussion of principles. Journal of Hydrology, 10(3): 282-290.

Natural Resources Canada 2016. Canadian Digital Elevation Model Mosaic. URL: http://geogratis.gc .ca/site/eng/extraction (Accessed February 22, 2016).

Overton, D.E. 1966. Muskingum flood routing of upland streamflow. Journal of Hydrology, 4: 185-200.

Quick, M.C., \& A. Pipes. 1977. UBC watershed model/Le modèle du bassin versant UCB. Hydrological Sciences Journal, 22(1): 153-161.

R Core Team 2016. R: A language and environment for statistical computing. R Foundation for Statistical Computing, Vienna, Austria. R version 3.3.1. URL: https://www.R-project.org/ (Accessed June 21, 2016).

Razavi, S., B.A. Tolson, L.S. Matott, N.R. Thomson, A. MacLean, \& F.R. Seglenieks. 2010. Reducing the computational cost of automatic calibration through model preemption. Water Resources Research, 46(11): 1-13. 
Razavi, T., \& P. Coulibaly. 2012. Streamflow prediction in ungauged basins: Review of regionalization methods. Journal of Hydrologic Engineering, 18(8): 958-975.

Rosenberg, E.A., A.W. Wood, \& A.C. Steinemann. 2011. Statistical applications of physically based hydrologic models to seasonal streamflow forecasts. Water Resources Research, 47(3): 1-19.

Schneider, T. 2001. Analysis of incomplete climate data: Estimation of mean values and covariance matrices and imputation of missing values. Journal of Climate, 14(5): 853-871.

Stahl, K., R. Moore, J. Shea, D. Hutchinson, \& A. Cannon. 2008. Coupled modelling of glacier and streamflow response to future climate scenarios. Water Resources Research, 44(2): 1-13.

Tolson, B.A., \& C.A. Shoemaker, 2007. Dynamically dimensioned search algorithm for computationally efficient watershed model calibration. Water Resources Research, 43(1): 1-16.

Tolson, B.A., \& C.A. Shoemaker. 2008. Efficient prediction uncertainty approximation in the calibration of environmental simulation models. Water Resources Research, 44(4): 1-19.

Vogel, R.M. 2006. Regional calibration of watershed models. Watershed Models, 45, 47-74.

Wang, T., A. Hamann, D.L. Spittlehouse, \& T.Q. Murdock. 2012. ClimateWNA-high-resolution spatial climate data for western North America. Journal of Applied Meteorology and Climatology, 51(1): 16-29.

Water Survey of Canada. 2016. Water office. URL: http://wateroffice.ec.gc.ca. (Accessed February 2, 2016). 